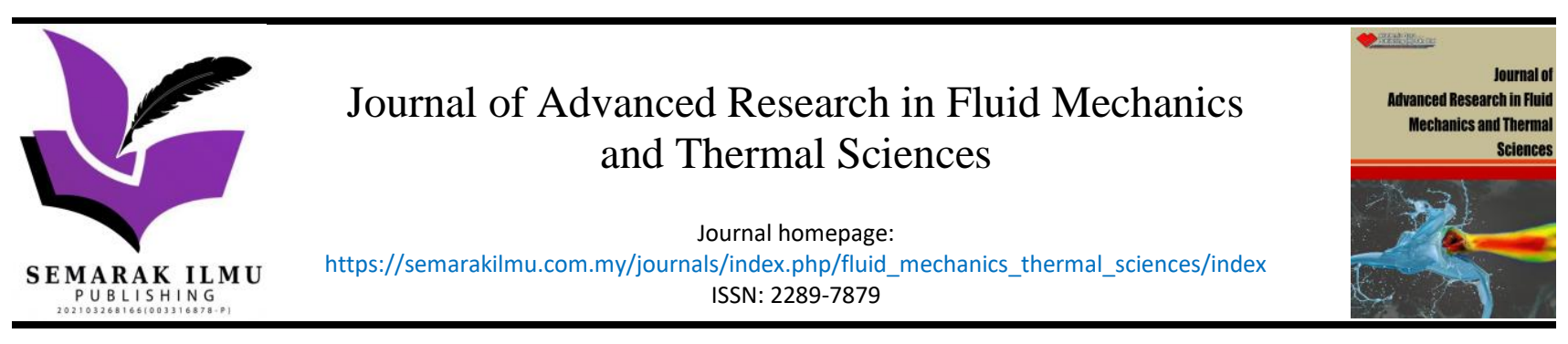

\title{
Wind Energy Potential on A Highrise Building: A Preliminary Study
}

\author{
Nofirman Firdaus ${ }^{1,2, *}$, Bambang Teguh Prasetyo ${ }^{3}$, Hasnida Ab-Samat ${ }^{2}$, Prayudi $^{1}$, Hendri ${ }^{1}$, Wahirom ${ }^{1}$, \\ Heri Suyanto ${ }^{4}$, Rusjdi Halim ${ }^{1}$
}

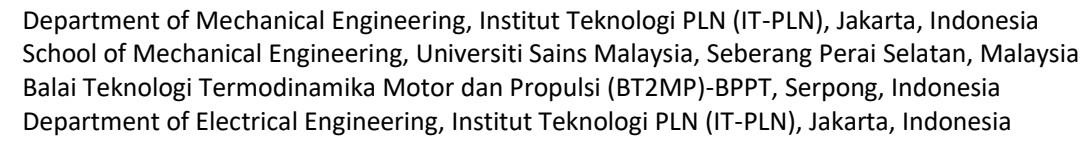

\section{ARTICLE INFO}

\section{Article history:}

Received 27 July 2021

Received in revised form 25 September 2021

Accepted 8 October 2021

Available online 6 November 2021

\section{Keywords:}

Wind energy; wind turbines; vertical axis wind turbines (VAWT); horizontal axis wind turbine (HAWT); high-rise buildings

\section{ABSTRACT}

Indonesia has an abundant renewable energy source. One of them is wind energy resources. Unfortunately, Indonesia's wind energy resource is not fully utilized, especially for application in high-rise buildings. The paper investigates the potential of energy production from the horizontal-axis wind turbine (HAWT) and the vertical-axis wind turbine (VAWT) on the rooftop of a university building in Indonesia. The wind speed data were measured on the rooftop of the building for seven months. The data was analyzed using Weibull distribution. Based on the probability density function of the Weibull distribution, the potential energy production was calculated using the power curves from the manufacturer. Comparing energy production between HAWTs and VAWTs has shown that VAWTs can produce more energy than HAWTs. Using six turbines, VAWTs can produce $48,476 \mathrm{kWh}$. On the other hand, with four turbines, HAWTs can produce $41,729 \mathrm{kWh}$. The reason is that VAWT requires shorter distance requirements for inter-turbine and between rows. Therefore, VAWT can use more turbines than HAWT in the limited area. In conclusion, VAWT for high-rise buildings is more preferred because VAWT can generate more energy. Further study should investigate the optimal configuration with varying the wind direction and quantifying the wake effect on power output.

\section{Introduction}

Indonesia has enormous potential for renewable energy in different types, such as hydro, geothermal, bioenergy, solar, ocean, and wind energy. According to Indonesia's ministry of energy and mineral resources, renewable energy's potential power is about $417,8 \mathrm{GW}$, but only $10,4 \mathrm{GW}$ has been utilized [1]. For wind energy, it has a potential power of 60,6 GW [2]. This data indicates wind energy potential has not been fully utilized.

In 2014, wind turbines' installed capacity was only 1.6 MW in Indonesia [3]. However, this number increased in 2018 with wind farm construction in two locations: Sidrap and Jeneponto, Sulawesi [4].

\footnotetext{
* Corresponding author.

E-mail address: nofirman@itpln.ac.id
}

https://doi.org/10.37934/arfmts.88.3.2030 
The Sidrap wind farm has 30 turbines with each turbine capacity of $2.5 \mathrm{MW}$, while the Jeneponto wind farm has 20 units of turbines with an individual capacity of 3.6 MW [4].

Wind energy can be utilized onshore, offshore, in mountains, valleys, and urban areas [5,6]. One of the promising wind energy applications is in high-rise buildings. High-rise buildings are a building with a minimum height of between 23 and 30 meters [7]. The potential for wind energy utilization in high-rise buildings is promising in Jakarta because it has hundreds of high-rise buildings; 91 buildings have a height of over 150 meters.

However, research on Indonesia's wind energy potential is limited, especially for high-rise buildings. One of which was performed by Tjahjana et al., [8] in Surakarta. For this research, the wind speed was measured at an altitude of 50 meters for five years, from January 2011 to December 2015. It was found that wind potential in Surakarta had an average wind speed of $4 \mathrm{~m} / \mathrm{s}$ and $5 \mathrm{~m} / \mathrm{s}$ with an occurrence frequency of $35.90 \%$ [8]. The wind energy potential in Surakarta had a wind density of $139.43 \mathrm{~W} / \mathrm{m}^{2}$ and potential electricity production of $1221.4 \mathrm{kWh} / \mathrm{m}^{2} /$ year [8]. Wind energy potential was analyzed using the Weibull distribution.

The second research of wind energy potential on a high-rise building was carried out in the main campus building with a height of $98 \mathrm{~m}$ [9]. Wind measurements were carried out at the height of $1 \mathrm{~m}$ (+ $98 \mathrm{~m})$ using an anemometer for eight months, from July to October and December until April. As a result, the average wind speed was $5.2 \mathrm{~m} / \mathrm{s}$, which could produce 100,000 kWh / year on the rooftop with a surface area of $796.25 \mathrm{~m} 2$. This electricity production had the potential to save electricity consumption on the main building by $3.27 \%$.

Due to the limited study on wind energy potential in high-rise buildings in Indonesia, therefore, this study aimed to analyze wind energy potential on the main building of the Institut Teknologi PLN (IT-PLN), which is in Jakarta, the capital of Indonesia. The main building has a height of $53.5 \mathrm{~m}$ and eleven floors, as shown in Figure 1. The rooftop area is a rectangular shape with a dimension of $33 \mathrm{~m}$ on each side. The wind speed was measured using an anemometer for seven months.

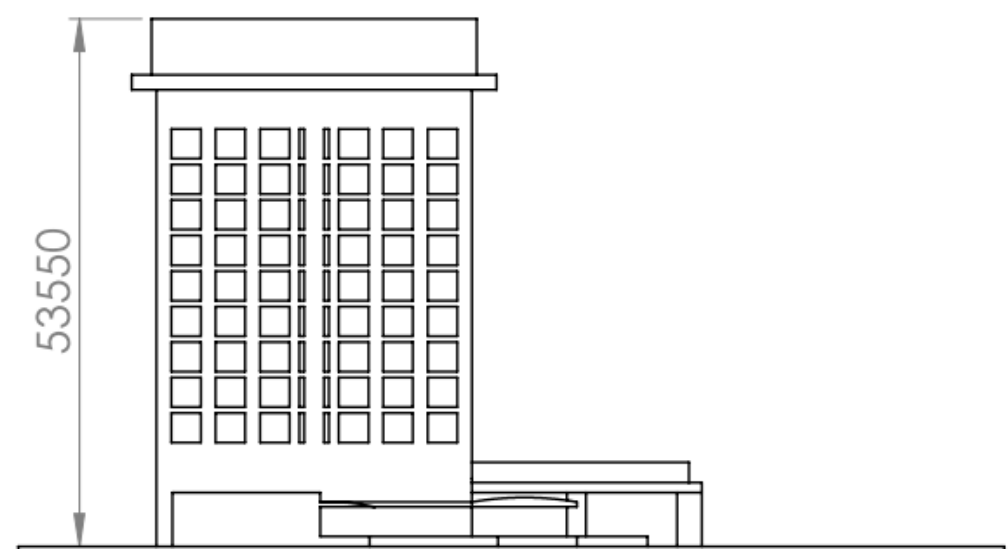

Fig. 1. Main campus building of IT-PLN

\section{Methodology}

Wind speed data for the research were measured using an anemometer installed on the building's rooftop at $1 \mathrm{~m}(+55.5 \mathrm{~m})$. The wind speed was recorded at the 12 -minute interval for seven months. The wind speed was then averaged hourly by using Eq. (1) [10].

$V_{m}=\left[\frac{1}{n} \sum_{i=1}^{n} v_{i}^{3}\right]^{1 / 3}$ 
Because the data was in time-series format, the wind speed data were sorted into bins. The frequency of wind speed in each bin was then counted. Both bins and the frequency of wind speed show the wind speed frequency distribution (Table 1). The wind speed data was then analyzed to determine two parameters of Weibull distribution using the standard deviation method (STDM), which is also considered as the empirical method [11,12]. This method is considered as a special of the moment method [13]. The Weibull shape parameter $k$ can be calculated by Eq. (2) [14].

$\left(\frac{\sigma_{v}}{V_{m}}\right)^{2}=\frac{\Gamma\left(1+\frac{2}{k}\right)}{\Gamma^{2}\left(1+\frac{1}{k}\right)}-1$

Where $\sigma_{v}$ is the standard deviation of the wind speed data set, the $V_{m}$ is the average wind speed in Table 2, and it is given by Eq. (3) [15]. The $f i$ is the frequency of wind speed (third column in Table $2)$, and $V_{i}$ is the mean wind speed for each bin in Table 2.

$V_{m}=\frac{1}{n} \sum_{i=1}^{n} f_{i} V_{i}$

Once $k$ is known, the scale parameter $c$ is given by [14]

$c=\frac{V_{m}}{\Gamma\left(1+\frac{1}{k}\right)}$

Alternatively, the scale parameter c can be estimated by [16]

$c=\frac{V_{m} k^{2.6674}}{0.184+0.816 k^{2.73855}}$

When the Weibull parameters were obtained, the probability of each bin was calculated, and the result was used to estimate the potential of energy production. The potential energy production was computed for a horizontal axis wind turbine (HAWT) and a vertical axis wind turbine (VAWT). The result is shown in Table 1.

Table 1

Turbine model used for the analysis

\begin{tabular}{lllll}
\hline No. & Turbine model & Turbin type & $\begin{array}{l}\text { Power } \\
(\mathrm{kW})\end{array}$ & $\begin{array}{l}\text { Diameter } \\
(\mathrm{m})\end{array}$ \\
\hline 1 & Fortis Montana & HAWT & 5.6 & 5 \\
2 & Ropatec WRE.060 & VAWT & 6 & 3.3 \\
\hline
\end{tabular}

\section{Results and Discussion}

\subsection{Wind Speed Distribution and Weibull Parameters}

Wind speed frequency distribution is the frequency of occurrence of wind speed in each bin. Wind speed frequency distribution is based on measured data, and it is essential to assess the wind energy potential. Wind turbines located at two different sites with the same wind speed may generate completely different energy output because of the difference in the wind speed distribution [17]. Therefore, wind measurement at the potential sites cannot be neglected. With the data in Table 2 and Eq. (3), the average wind speed is $6.4 \mathrm{~m} / \mathrm{s}$. 
The frequency distribution is required to calculate the Weibull parameters using STDM. Based on Table 2, the Weibull parameter can be calculated using Eq. (2) and Eq. (4). The Weibull parameters are 2.09 for the $k$ and 7.23 for the $c$ parameter.

The application of the STDM method to estimate energy production is considerably accurate. For example, a study showed that potential energy error at three different sites was between $0,7 \%$ and $3,6 \%$ by using STDM [12]. Another study found that the error in power density calculation at three different heights was between $0,12 \%$ and $3,5 \%$.

Table 2

Wind speed frequency distribution based on measured data for seven months

\begin{tabular}{lllll}
\hline \multicolumn{2}{l}{$\mathrm{Vi}(\mathrm{m} / \mathrm{s})$} & & $\mathrm{Vi}(\mathrm{m} / \mathrm{s})$ & Frequency \\
\hline 0 & - & 1 & 0.5 & 0.0079 \\
1 & - & 2 & 1.5 & 0.0461 \\
2 & - & 3 & 2.5 & 0.0919 \\
3 & - & 4 & 3.5 & 0.1418 \\
4 & - & 5 & 4.5 & 0.1142 \\
5 & - & 6 & 5.5 & 0.0766 \\
6 & - & 7 & 6.5 & 0.1359 \\
7 & - & 8 & 7.5 & 0.0604 \\
8 & - & 9 & 8.5 & 0.0713 \\
9 & - & 10 & 9.5 & 0.1264 \\
10 & - & 11 & 10.5 & 0.0538 \\
11 & - & 12 & 11.5 & 0.0299 \\
12 & - & 13 & 12.5 & 0.0114 \\
13 & - & 14 & 13.5 & 0.0101 \\
14 & - & 15 & 14.5 & 0.0135 \\
15 & - & 16 & 15.5 & 0.0026 \\
16 & - & 17 & 16.5 & 0.0058 \\
17 & - & 18 & 17.5 & 0.0003 \\
\hline
\end{tabular}

\subsection{Potential of Energy Production for a Single Wind Turbine}

The Weibull parameters are used to calculate each bin's probability density function and applied to calculate the probability of potential energy production for different turbine models.

The power curve data is required to estimate energy output in the 4th column in Table 3 accurately. The power curve is the relation between the wind speed and the power output of the wind turbine. The power curve data were taken from the manufacturer's data, as illustrated in Figure 2 [18]. The probability density function based on Weibull parameters was used to estimate the percentage of wind speed occurrence in each bin, and it was then used to calculate energy production, as shown in Table 3. For a $6 \mathrm{~kW}$ HAWT, the cut-in and rated wind speed are $2.5 \mathrm{~m} / \mathrm{s}$ and $17 \mathrm{~m} / \mathrm{s}$, respectively; therefore, the $6 \mathrm{~kW}$ HAWT starts generating power at a wind speed of $2.5 \mathrm{~m} / \mathrm{s}$ and reaches its rated-power at a wind speed of $17 \mathrm{~m} / \mathrm{s}$. 
Table 3

Prediction of the annual energy output for $6 \mathrm{~kW}$ of VAWT

\begin{tabular}{llllll}
\hline $\begin{array}{l}\text { Minimum } \\
(\mathrm{m} / \mathrm{s})\end{array}$ & $\begin{array}{l}\text { Maximum } \\
(\mathrm{m} / \mathrm{s})\end{array}$ & $\begin{array}{l}\text { Average } \\
(\mathrm{m} / \mathrm{s})\end{array}$ & $\begin{array}{l}\text { Power } \\
(\mathrm{kW})\end{array}$ & $\begin{array}{l}\text { Probability } \\
\text { Energy } \\
\text { kWh }\end{array}$ \\
\hline 4 & 4 & 3.5 & 0.08 & $10.51 \%$ & 69 \\
5 & 5 & 4.5 & 0.18 & $11.94 \%$ & 183 \\
6 & 6 & 5.5 & 0.33 & $12.29 \%$ & 350 \\
7 & 7 & 6.5 & 0.55 & $11.67 \%$ & 562 \\
8 & 8 & 7.5 & 0.85 & $10.32 \%$ & 768 \\
9 & 9 & 8.5 & 1.25 & $8.55 \%$ & 937 \\
10 & 10 & 9.5 & 1.75 & $6.67 \%$ & 1,022 \\
11 & 11 & 10.5 & 2.35 & $4.91 \%$ & 1,010 \\
12 & 12 & 11.5 & 3.10 & $3.41 \%$ & 926 \\
13 & 13 & 12.5 & 4.00 & $2.24 \%$ & 785 \\
14 & 14 & 13.5 & 5.05 & $1.39 \%$ & 617 \\
15 & 15 & 14.5 & 5.80 & $0.82 \%$ & 418 \\
16 & 16 & 15.5 & 6.00 & $0.46 \%$ & 241 \\
17 & 17 & 16.5 & 6.00 & $0.24 \%$ & 128 \\
& 18 & 17.5 & 6.00 & $0.12 \%$ & 64 \\
& \multicolumn{5}{l}{ Total energy production for 1 turbine: } \\
\hline
\end{tabular}

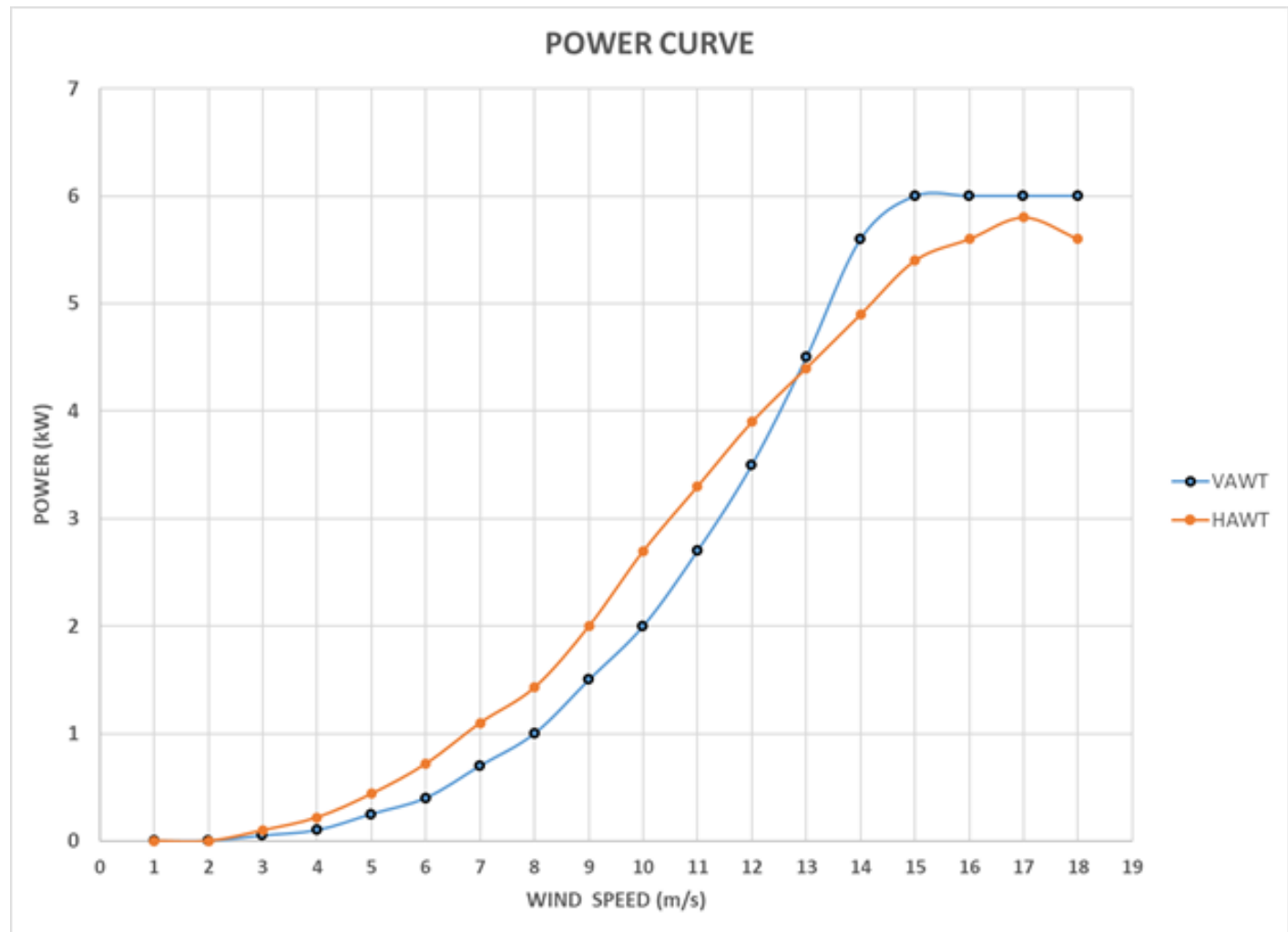

Fig. 2. Power curves of HAWT and VAWT [18]

Although the HAWT has a slightly lower rated power than VAWT, the potential energy production and the capacity factor (CF) of HAWT are larger than VAWT (Table 4). The reason is that $82 \%$ of wind speed frequency occurred at mean wind speed between $3.5 \mathrm{~m} / \mathrm{s}$ and $12.5 \mathrm{~m} / \mathrm{s}$ (Table 2), and the power curve of HAWT has a higher power on those wind speed range than VAWT (Figure 2). 
The energy output of HAWT using measured data in Table 2 is 10,567 kWh. Comparing the energy output between measured data and Weibull distribution data shows that the energy output error for HAWT is within $\pm 1.28 \%$, and for VAWT is within $\pm 0.56 \%$.

Table 4

\begin{tabular}{llll}
\multicolumn{4}{c}{ Annual energy production and capacity factor } \\
\hline No. & Turbine type & $\begin{array}{l}\text { Energy } \\
\text { (kWh) }\end{array}$ & CF \\
\hline 1 & HAWT & 10,432 & $21 \%$ \\
2 & VAWT & 8,079 & $15 \%$ \\
\hline
\end{tabular}

\subsection{Energy Potential Production for Multiple Turbines}

Multiple turbines are usually used in a wind farm to increase energy output. However, the size and the number of the wind turbine that can be used on the building is limited by the available rooftop area, and the capability of the building structure to withstand the weight and the vibration of the turbine during operation because most buildings are not designed to use wind turbine.

For optimal wind turbine operation, the distance between turbines and the distance between turbine rows have specific requirements for each turbine type. For example, for HAWT type, the recommended inter-turbine spacing $(S x)$ is between 3D and $5 D$ ( $D$ is the rotor diameter), and the spacing between rows (Sy) is between 5D and 9D [19]. Therefore, four HAWTs with in-line arrangements can be used on the rooftop area, as illustrated in Figure 3. The base output power is around $22.4 \mathrm{~kW}$, and the estimate of annual energy generation is $41,729 \mathrm{kWh}$ without considering the wake effect to the downstream turbines and the variation of wind direction.

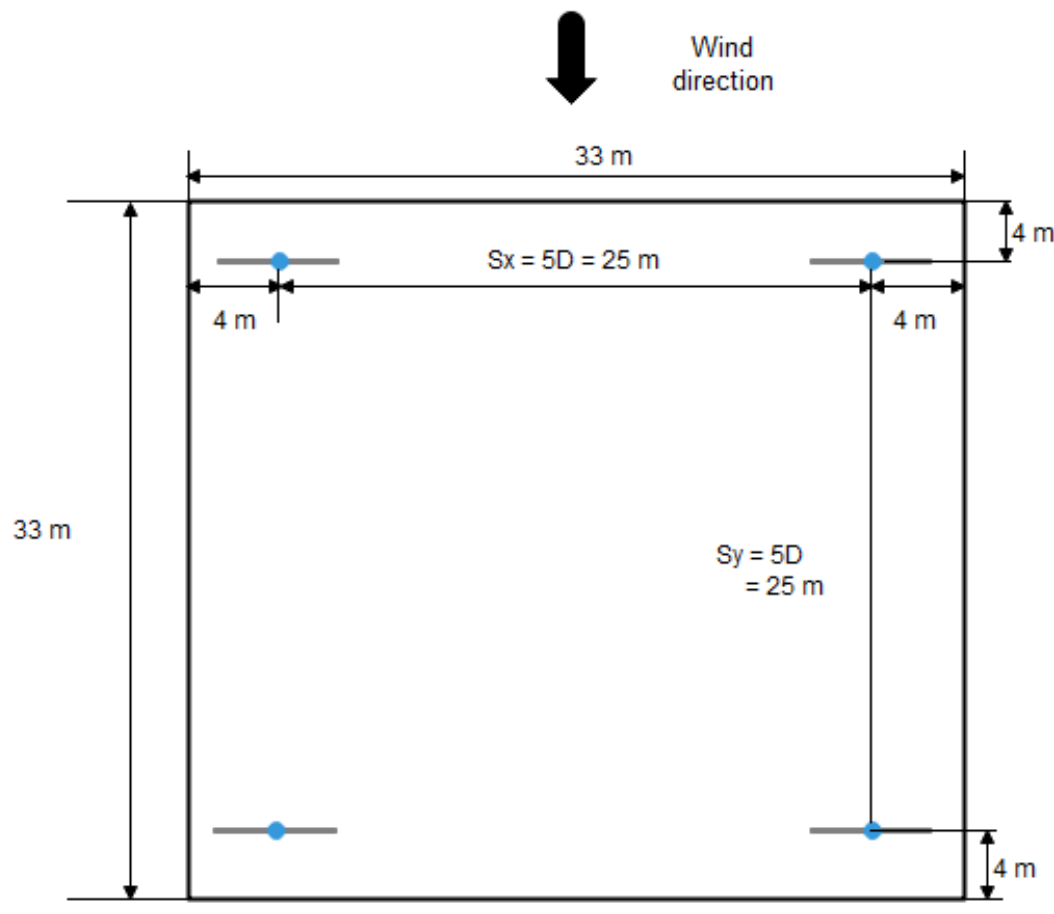

Fig. 3. Turbine spacing for HAWT

Contrary to HAWT, the performance of VAWT is not sensitive to the spacing between turbines. For VAWT, a shorter distance between turbines leads to a slight decrease in performance, but in some cases, the shorter spacing may increase the power Cp of VAWTs [20,21]. A study recommended 
that the spacing inter-turbine was $1.36 \mathrm{D}$ for the best performance, especially for counter-rotating between adjacent turbines. The accelerated streamflow between turbines is the main reason for the performance improvement [21,22]. Another study showed that the best spacing between turbines was 3D for varying wind direction [23].

For our study, the distance between turbines and rows is planned to be $4 \mathrm{D}$ and $8.5 \mathrm{D}$, respectively, as shown in Figure 4. Therefore, there will be three turbines for each row or six turbines overall. According to Dabiri [24], four diameter distances between turbines and rows only reduces the power output by $5 \%$ compared with an isolated turbine. With the distance to the downstream turbines equal to 8.5 of rotor diameter, the VAWT may generate at least the same power as an isolated turbine when wind direction is from north or south. The multiples VAWT will have an installed capacity of 36 $\mathrm{kW}$. The annual energy generation is around $48,476 \mathrm{kWh}$.

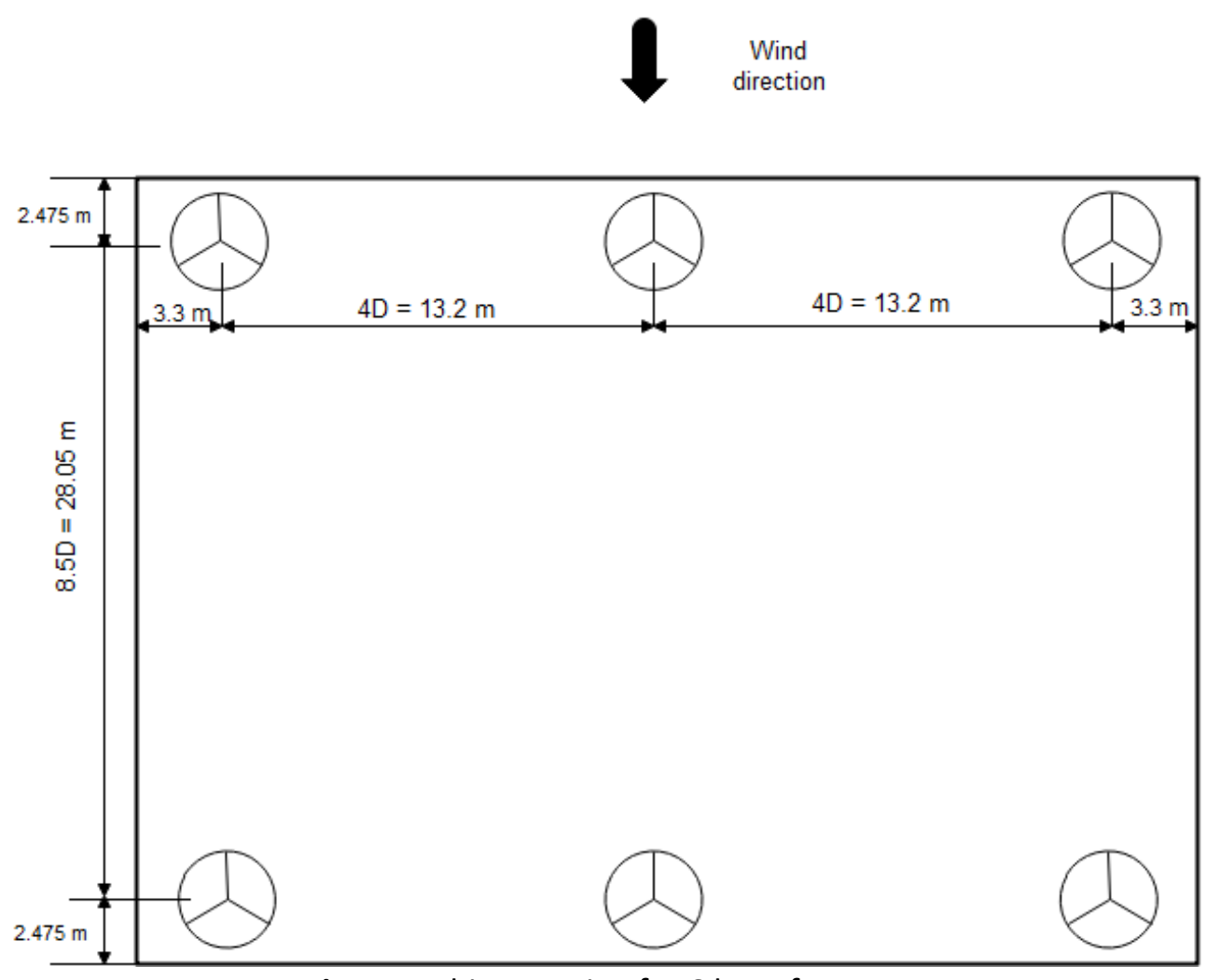

Fig. 4. Turbine spacing for $6 \mathrm{~kW}$ of VAWTs

Comparing the potential energy production between VAWTs and HAWTs shows that the VAWTs generate more energy by $14 \%$. The reason is that VAWT has a lower distance requirement between turbines and rows. Therefore, more units of VAWT can be used. Also, for wind turbine application on the rooftop area of a high-rise building, where the space is very limited, the VAWT is more preferred than HAWT.

Without considering the wake effect, the four turbines of HAWT may generate four times of energy of an isolated HAWT from any direction, as previously discussed. However, for an actual wind condition (Figure 5), the downstream turbine may have a wake effect because the wind speed after the upstream turbines decreases. Consequently, the power output and energy generation of the downstream turbine are lower. According to Bons [25], the wake region may go as far as a six-turbine diameter at $20^{\circ}$ degree behind each turbine. On the other hand, the rooftop area of the building is very limited. It is not preferred to have a spacing of $6 \mathrm{D}$ to the downstream turbines unless a smaller turbine size is used. As a result, the wake effect reduces the downstream turbine's power output 
from $20 \%$ to $46 \%$ compared to the power output of an isolated turbine [26]. The most considerable losses are $46 \%$ at a distance of Sy/D $=3$.

However, the power output of HAWT can be improved in several ways: operating upstream turbine at the yawed position and optimizing the turbine layout. By yawning upstream turbine position during operation, the wake effect on the downstream turbine is lesser. Therefore, the output power can increase by $12 \%$ [26]. The following improvement is by changing the arrangement from in-line to staggered configuration. Applying the staggered layout may improve the energy output and power factor by $5.5 \%$ and $7.8 \%$, respectively [27]. Another strategy is that staggering the turbines in vertical may improve the power output by $15 \%$ [28].

By contrast, the distance between turbines of VAWT has a lower requirement. Because of the lower distance requirement, the performance and power output of the VAWT can be improved in two ways: shortening the distance between VAWT and clustering the VAWT. The distance interturbine of VAWT can be shortened to $1.36 \mathrm{D}$, improving power production by $10 \%$ [21]. For the current VAWT layout (Figure 4), eight more turbines can be added to the layout with a spacing of 1.36D. Consequently, the power output at rated-power may increase from $36 \mathrm{~kW}$ to $84 \mathrm{~kW}$.

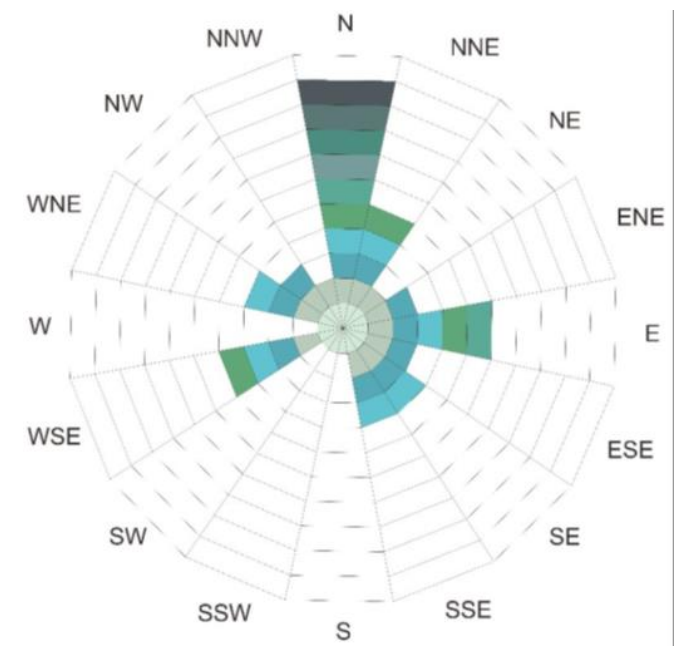

Fig. 5. Wind rose based on the frequency

Another improvement strategy can be achieved by clustering the VAWT. The clustering can be in biomimetic, three turbines cluster, and four turbines cluster $[29,30]$. The interaction between VAWTs may result in a $10 \%$ improvement in power output [30]. Another benefit of clustering the VAWT is that it can work well from any wind direction. Improving our current layout (Figure 4) into clustering will increase the power output because at least six VAWTs can be added to the layout.

Another factor that should be considered is the effect of the vibration of a wind turbine on the building. The vibration of the wind turbine can cause fatigue to the building structure [31]. To understand the effects, some researchers already studied the issues. First is the studying of the effect of a wind turbine on the building that could cause tactile (feelable) vibration, the rattling of fixtures and fittings, and damage to the building [32]. The case studies were performed on four different buildings. The result showed that there was no evidence either from measurement and the tenants on tactile vibration, the rattling of fixtures and fittings, and (potential) damage to the building.

Another study was performed on the rooftop of 24 story building [33]. The result showed that building vibration contributed to the vibration of the VAWT tower, not the other way around. Therefore, further study is worth investigating the effect of vibration of multiple turbines on the building and exploring mitigation strategies to reduce the vibration of VAWT. 
To install the turbine, the VAWT should be disassembled into some parts. Therefore, it will be easier to transport to the rooftop of the building either by using a cradle system or a good elevator. The parts are then assembled on the rooftop.

\section{Conclusions}

The potential application of wind turbines on the rooftop of a high-rise building has been investigated. The wind data was measured using an anemometer for seven months. The average wind speed is $6.40 \mathrm{~m} / \mathrm{s}$, which is potential for further study. The annual energy production potential for a single turbine is 10,432 kWh and 8,079 kWh for HAWT and VAWT, respectively. Based on energy production, HAWT is more superior for single turbine operation than VAWT. The reason is that HAWT has a better power curve that generates more power on wind speed range between $3.5 \mathrm{~m} / \mathrm{s}$ and 12.5 $\mathrm{m} / \mathrm{s}$. This wind speed range contributes to $82 \%$ of wind occurrence.

However, when it comes to multiple turbine applications, VAWT is more superior to HAWT. VAWT needs a lower spacing requirement than HAWT; therefore, it can utilize more turbine units. The HAWT can use four turbines with a total capacity of $22.4 \mathrm{~kW}$ and generate $41,729 \mathrm{kWh}$. On the other hand, VAWT can employ eight turbines with a total capacity of $36 \mathrm{~kW}$ and generate $48,476 \mathrm{kWh}$. Also, HAWT may suffer from a wake effect that leads to significantly lower power output.

Some improvement techniques to increase power and energy output has been identified from the literature. For HAWT, the power output can be improved by yawning the turbine position to reduce the wake effect on the downstream turbine and staggering the layout horizontally and vertically. Improvement strategies have also been found for VAWT: shortening the spacing between turbines and rows and clustering the VAWT layout. Either way may permit the use of additional turbines, which consequently increase the power output of windfarm. Therefore, the application of VAWT is more preferred than HAWT because the improvement can increase the power output significantly.

Further studies are needed to identify the effect of wake effect on the power output of current arrangement for HAWT and VAWT by varying wind direction according to Figure 5. Secondly, the proposed improvement strategies for HAWT and VAWT should be further investigated to quantify the effect of improvement on each turbine type's power output. The studies should be performed by either CFD analysis or experimental studies using a wind tunnel.

\section{Acknowledgement}

This research was funded by a grant from Institut Teknologi PLN, Jakarta, Indonesia.

\section{References}

[1] Humas. "Strategi Pemerintah Hadapi Tantangan Pengembangan EBT Nasional." Direktorat Jenderal Energi Baru Terbarukan dan Konservasi Energi (EBTKE), Septermber 10, 2020. https://ebtke.esdm.go.id/post/2020/09/28/2641/strategi.pemerintah.hadapi.tantangan.pengembangan.ebt.nasi onal.

[2] Susan, Susan, and Dyah Kusuma Wardhani. "Photovoltaic and Wind Turbine: A Comparison as Building Integrated Renewable Energy in Indonesia." Humaniora 11, no. 1 (2020): 51-57. https://doi.org/10.21512/humaniora.v11i1.6294

[3] Martosaputro, Soeripno, and Nila Murti. "Blowing the wind energy in Indonesia." Energy Procedia 47 (2014): $273-$ 282. https://doi.org/10.1016/i.egypro.2014.01.225

[4] Barus, Dhany Harmeidy, and Rinaldy Dalimi. "The Integration of Wind Power Plants to Southern Sulawesi Power System." In 2020 International Conference on Electrical, Communication, and Computer Engineering (ICECCE), pp. 1-6. IEEE, 2020. https://doi.org/10.1109/ICECCE49384.2020.9179480

[5] Pichitkul, Auraluck, and Lakshmi N. Sankar. "Aerodynamic design and modeling of large-scale offshore wind 
turbines." CFD Letters 11, no. 10 (2019): 1-14.

[6] Mazlan, Mohamad Zahid, Fazila Mohd Zawawi, Teeab Tahzib, Kamarulafizam Ismail, and Syahrullail Samion. "Performance Analysis of Highway Wind Turbine Enhanced with Wind Guide Vanes Using the Taguchi Method." CFD Letters 13, no. 3 (2021): 25-42. https://doi.org/10.37934/cfdl.13.3.2542

[7] Craighead, G. "High-rise building definition, development, and use." High-Rise Cecurity and Fire Life Safety, 3rd ed.; Butterworth-Heinemann: Boston, MA, USA (2009). https://doi.org/10.1016/B978-1-85617-555-5.00001-8

[8] Tjahjana, Dominicus Danardono Dwi Prija, Arnold Thamrin Halomoan, Andreas Wibowo, Dwi Aries Himawanto, and Yoga Arob Wicaksono. "Wind potential assessment in urban area of Surakarta city." In AIP Conference Proceedings, vol. 1931, no. 1, p. 030070. AIP Publishing LLC, 2018. https://doi.org/10.1063/1.5024129

[9] Soebiyan, Vivien, J. F. Bobby Saragih, and Michael Tedja. "Study on high-rise building using wind energy at humid tropical climate." Chemical Engineering Transactions 56 (2017): 241-246.

[10] Mathew, Sathyajith. Wind energy: fundamentals, resource analysis and economics. Vol. 1. Berlin: Springer, 2006. https://doi.org/10.1007/3-540-30906-3

[11] Kumar, K. Shiva Prashanth, and Satyanarayana Gaddada. "Statistical scrutiny of Weibull parameters for wind energy potential appraisal in the area of northern Ethiopia." Renewables: Wind, Water, and Solar 2, no. 1 (2015): 1-15. https://doi.org/10.1186/s40807-015-0014-0

[12] Chang, Tian Pau. "Performance comparison of six numerical methods in estimating Weibull parameters for wind energy application." Applied Energy 88, no. 1 (2011): 272-282. https://doi.org/10.1016/j.apenergy.2010.06.018

[13] Mohammadi, Kasra, Omid Alavi, Ali Mostafaeipour, Navid Goudarzi, and Mahdi Jalilvand. "Assessing different parameters estimation methods of Weibull distribution to compute wind power density." Energy Conversion and Management 108 (2016): 322-335. https://doi.org/10.1016/i.enconman.2015.11.015

[14] Justus, C. G., W. R. Hargraves, Amir Mikhail, and Denise Graber. "Methods for estimating wind speed frequency distributions." Journal of Applied Meteorology 17, no. 3 (1978): 350-353. https://doi.org/10.1175/15200450(1978)017<0350:MFEWSF>2.0.CO;2

[15] Celik, Ali Naci. "Energy output estimation for small-scale wind power generators using Weibull-representative wind data." Journal of Wind Engineering and Industrial Aerodynamics 91, no. 5 (2003): 693-707. https://doi.org/10.1016/S0167-6105(02)00471-3

[16] Balouktsis, Anastasios, Dimitrios Chassapis, and Thodoris D. Karapantsios. "A nomogram method for estimating the energy produced by wind turbine generators." Solar Energy 72, no. 3 (2002): $251-259$. https://doi.org/10.1016/S0038-092x(01)00099-8

[17] Tong, Wei. Wind power generation and wind turbine design. WIT press, 2010.

[18] Urbanwind. "Catalogue of European Urban Wind Turbine Manufacturers." Wind Energy Integration in the Urban Environment (WINEUR), 2011. http://www.urbanwind.net/pdf/CATALOGUE V2.pdf.

[19] Gupta, Neeraj. "A review on the inclusion of wind generation in power system studies." Renewable and Sustainable Energy Reviews 59 (2016): 530-543. https://doi.org/10.1016/j.rser.2016.01.009

[20] Whittlesey, Robert W., Sebastian Liska, and John O. Dabiri. "Fish schooling as a basis for vertical axis wind turbine farm design." Bioinspiration \& Biomimetics 5, no. 3 (2010): 035005. https://doi.org/10.1088/1748$3182 / 5 / 3 / 035005$

[21] Giorgetti, Simone, Giulio Pellegrini, and Stefania Zanforlin. "CFD investigation on the aerodynamic interferences between medium-solidity Darrieus Vertical Axis Wind Turbines." In 69th Conference of the Italian-ThermalEngineering-Association (ATI), vol. 81, pp. 227-239. Elsevier, 2015. https://doi.org/10.1016/i.egypro.2015.12.089

[22] Didane, Djamal Hissein, Muhammad Amir Zafran Saipul Anuar, Mohd Faizal Mohideen Batcha, Kamil Abdullah, Mas Fawzi Mohd Ali, and Akmal Nizam Mohammed. "Simulation Study on the Performance of a Counter-rotating Savonius Vertical Axis Wind Turbine." CFD Letters 12, no. 4 (2020): 1-11. https://doi.org/10.37934/cfdl.12.4.111

[23] Zanforlin, Stefania, and Takafumi Nishino. "Fluid dynamic mechanisms of enhanced power generation by closely spaced vertical axis wind turbines." Renewable Energy $99 \quad$ (2016): 1213-1226. https://doi.org/10.1016/j.renene.2016.08.015

[24] Dabiri, John O. "Potential order-of-magnitude enhancement of wind farm power density via counter-rotating vertical-axis wind turbine arrays." Journal of Renewable and Sustainable Energy 3, no. 4 (2011): 043104. https://doi.org/10.1063/1.3608170

[25] Bons, Nicolas. "Optimization of Vertical Axis Wind Turbine Farm Layout." American Institute of Aeronautics and Astronautics (2010).

[26] Adaramola, M. S., and P-Å. Krogstad. "Experimental investigation of wake effects on wind turbine performance." Renewable Energy 36, no. 8 (2011): 2078-2086. https://doi.org/10.1016/i.renene.2011.01.024

[27] González-Longatt, Francisco, P. Wall, and V. Terzija. "Wake effect in wind farm performance: Steady-state and dynamic behavior." Renewable Energy 39, no. 1 (2012): 329-338. https://doi.org/10.1016/i.renene.2011.08.053

[28] Zhang, Mengqi, and Richard J. A. M. Stevens. "Exploring a better turbine layout in vertically staggered wind farms." 
In Journal of physics: Conference Series, vol. 1037, no. 7, p. 072041. IOP Publishing, 2018. https://doi.org/10.1088/1742-6596/1037/7/072041

[29] Barnes, Andrew, and Ben Hughes. "Determining the impact of VAWT farm configurations on power output." Renewable Energy 143 (2019): 1111-1120. https://doi.org/10.1016/j.renene.2019.05.084

[30] Hezaveh, Seyed Hossein, Elie Bou-Zeid, John Dabiri, Matthias Kinzel, Gerard Cortina, and Luigi Martinelli. "Increasing the power production of vertical-axis wind-turbine farms using synergistic clustering." Boundary-layer Meteorology 169, no. 2 (2018): 275-296. https://doi.org/10.1007/s10546-018-0368-0

[31] Shinagam, Ramakrishna, Guntaka Ajay, Lokanadham Patta, and Anand Siva Gandam. "Vibration and noise studies on wind turbine generator for reduction of vibrations and noise." World Journal of Engineering 17, no. 1 (2020): 134-143. https://doi.org/10.1108/WJE-09-2019-0275

[32] Moorhouse, Andy, Andy Elliott, Graham Eastwick, Tomos Evans, Andy Ryan, Sabine von Hunerbein, Valentin le Bescond, and David Waddington. "Noise and vibration from building-mounted micro wind turbines Part 2: Results of measurements and analysis." University of Salford, Manchester (2011).

[33] Wang, Ying, Wensheng Lu, Kaoshan Dai, Miaomiao Yuan, and Shen-En Chen. "Dynamic study of a rooftop vertical axis wind turbine tower based on an automated vibration data processing algorithm." Energies 11, no. 11 (2018): 3135. https://doi.org/10.3390/en11113135 